\title{
ON THE VASODEPRESSIVE ACTION OF WARMED PLASMA IN CATS
}

\author{
AKIRA UENO \\ Department of Pharmacology, Nagasaki University School of Medicine, Nagasaki \\ Received for publication April 1, 1956
}

Much research has been made on the vasodepressive action of fresh defibrinated blood (1-5) and foreign serum (6-15). It is reported that histamine (16), acetylcholine (17), adenyl derivatives (18), etc., which contained blood, are the main substances, and furthermore that new substances as Kallikrein (19), substance P (20), substance Z (21), Felix-Lange's substance (22), Vesiglandin (23), and Bradykinin (24) which had their origin in living tissues brought down blood pressure.

Previously Hongo and Ueno (25) have found that an intravenous injection of plasma, warmed at $37^{\circ} \mathrm{C}$ for $18-24$ hours, showed a transitorily marked hypotensive effect on the blood pressure of cats.

It is the purpose of this experiment to show that this active substance which appeared in the warmed plasma has been pharmacologically investigated, especially with regard to the mechanism of the vasodepressive effect.

\section{MATERIALS AND METHODS}

The blood was chiefly obtained by heart puncture from healthy rabbits after they had been subjected to 24 hours' fasting. The injection syringe was dried after sterilization and frozen to check the coagulation. The blood was taken into the sterilized glass tube and before the blood coagulated the plasma was separated by centrifugation for $5 \mathrm{~min}(2,000-$. 3,000 r.p.m.) at cooling. Each procedure had to be done smoothly without letting blood coagulate during centrifugation, lest some hypotensive substances might be produced by the blood coagulation. Plasma for the experiments was kept in the incubator for 2-24 hours at $37^{\circ} \mathrm{C}$ before it was placed in baths at $0-50^{\circ} \mathrm{C}$ in order to observe the temperature influences on the potency of plasma.

Experiments for the potency of the plasma were carried out with adult cats narcotized with urethane or methylhexabital. The carotid artery pressure was measured by ordinary mercurial manometer and the pulmonary artery pressure by rolling manometer (26). The blood flow in the carotid and femoral artery was measured by the rolling manometer method of Ueno-Takenaka (26). The results obtained by the above measurements were recorded on the smoked paper of a kymographion. 


\section{A. UENO}

\section{EXPERIMENTAL RESULTS}

\section{Influence of rabbit blood on cat blood pressure}

To observe how normal constituents of rabbit plasma act on cats' blood pressure, fresh whole blood $0.2-0.5 \mathrm{cc}$ was injected to the femoral vein of a cat. The pressure lowered temporarily at first, and then the pressure kymogram was disturbed by heart failure (Fig. 1).

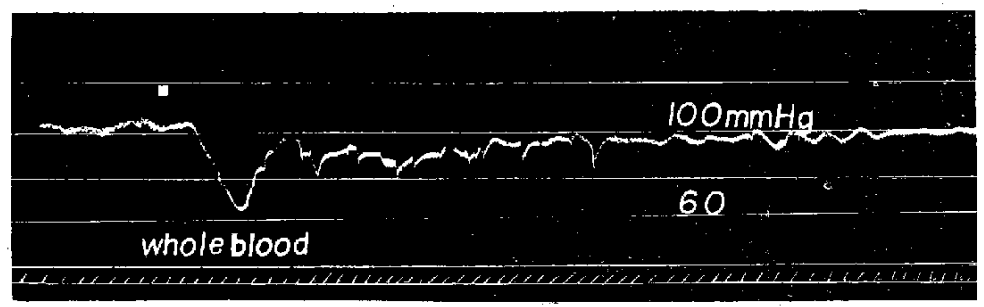

FiG. 1

It was the same in the case of using a small quantity of the blood containing heparin. Serum of $0.2-0.5 \mathrm{cc}$ separated from the coagulated blood was injected intravenously into a cat, so the marked fall of the blood pressure was observed temporarily. On the other hand, plasma, or serum gained from the plasma, coagulated without cells, showed no effect on the blood pressure.

It is considered that the plasma or the serum of the rabbit has no hypotensive action on cats' blood pressure, but some hypotensive substances appear in the fluid phase of blood after coagulation.

\section{Infuences of warmed plasma on circulation of cats}

Warmed plasma. A test was made to see how long rabbit plasma has to be warmed at $37^{\circ} \mathrm{C}$ to activate its hypotensive effect. When the plasma was warmed for 2 hours, it decreased the pressure by the intravenous injection of $0.5 \mathrm{cc}$. The longer the duration of warming up to 24 hours, the more intensive was the hypotensive effect. Nevertheless, activity did not increase so much after 24 hours.

The relation between the temperature in which the plasma is warmed for 24 hours and its vasodepressive effect was cxamined at $0^{\circ} \mathrm{C}, 4^{\circ} \mathrm{C}, 10^{\circ} \mathrm{C}, 20^{\circ} \mathrm{C}, 30^{\circ} \mathrm{C}, 35^{\circ} \mathrm{C}, 39^{\circ} \mathrm{C}, 40^{\circ} \mathrm{C}, 45^{\circ} \mathrm{C}$, and $50^{\circ} \mathrm{C}$, and was observed that the plasma (serum) kept over $40^{\circ} \mathrm{C}$ or under $20^{\circ} \mathrm{C}$ showed no hypotensive action on the blood pressure. So it is clear that the plasma becomes effective by warming from $30^{\circ} \mathrm{C}$ to $40^{\circ} \mathrm{C}$, especially from $35^{\circ} \mathrm{C}$ to $40^{\circ} \mathrm{C}$.

Such a hypotensive action of the plasma on cats was observed not only in plasma obtained from rabbits, but also in plasma from human blood or from cat blood. Therefore the experiments were made with plasma (serum) warmed at $37 \mathrm{C}$ for 24 hours, which is called only. "warmed plasma."

The warmed plasma had no influence on the pressure of rabbits, or on isolated intestines of rabbits, rats, or guinea pigs. If the plasma was contaminated by saprophytes, colored, or putrid, it showed no hypotensive action. 
Mode of decreasing blood pressure. When the warmed plasma $0.2-0.5 \mathrm{cc}$ was injected to the femoral vein of cats, the blood pressure showed a marked decrease (60-80\% of the original pressure). It soon recovered and reached the former level a few minutes later (Fig. 2). Such

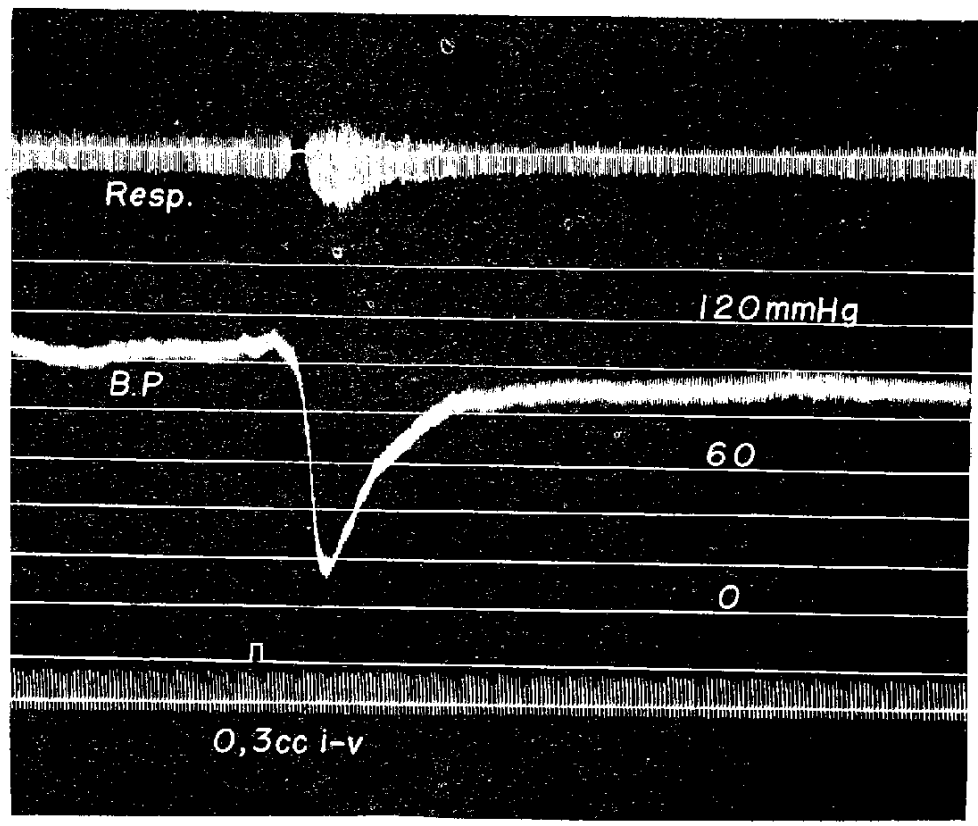

FIG. 2

vasodepressive action was most remarkable at the first injection, and then the effectiveness decreased rapidly after repeated injections. If the injections were given more than ten times, tachyphylactic phenomenon was observed and the hypotensive action completely disappeared. No animal died from such vasodepression in spite of severe symptoms.

Compared with acctylcholine, histamine, and Kallikrein, it was observed in many cats that these drugs acted vasodepressive like the warmed plasma, but the vasodepression continued longer than that by warmed plasma. These drugs did not show tachyphylaxis observed in the warmed plasma.

The hypotensive action of $0.25 \mathrm{cc}$ of the warmed plasma was diminished by a preliminary intravenous injection of atropine sulfate $3 \mathrm{mg} / \mathrm{kg}$, which was enough to prevent the action of acetylcholine.

Similarly, a foregoing intravenous injection of benadryl completely counteracting the histamine chloride $3 r$ did not inhibit the hypotensive action of the warmed plasma $0.25 \mathrm{cc}$.

Section of both vagal nerve made no difference in the action of warmed plasma, and the hypotensive effect of the warmed plasma on a cat whose spinal cord was cut off at $\mathrm{C}_{1}$ $-\mathrm{C}_{2}$ under artificial respiration was examined. Although it was difficult to compare with normal cases, as the blood pressure lowered to $30-40 \mathrm{~mm} \mathrm{Hg}$ after amputation, yet the intravenous injection of the warmed plasma $0.25 \mathrm{cc}$ apparently decreased the pressure. 
When the same amount of warmed plasma was injected into the carotid artery in normal animals, no difference was observed in the hypotensive actions. From the above observations it was made clear that the effect of warmed plasma has no relation with the brain.

When abdominal circulation was occluded by ligating the abdominal aorta, under the diaphragm, and then the warmed plasma was administered intravenously, the carotid pressure decreased as well as it did in normal cats.

Effects on blood flowe. In order to observe vasodilator and vasoconstrictor action, blood flow in the carotid and femoral artery was measured. The warmed plasma was injected into the common carotid artery and into the femoral vein. Unless the systemic blood pressure lowered, no change was observed in the blood flow. Meanwhile, however, the systemic blood pressure lowered several seconds later, and the blood flow in both arteries decreased markedly (Fig. 3).

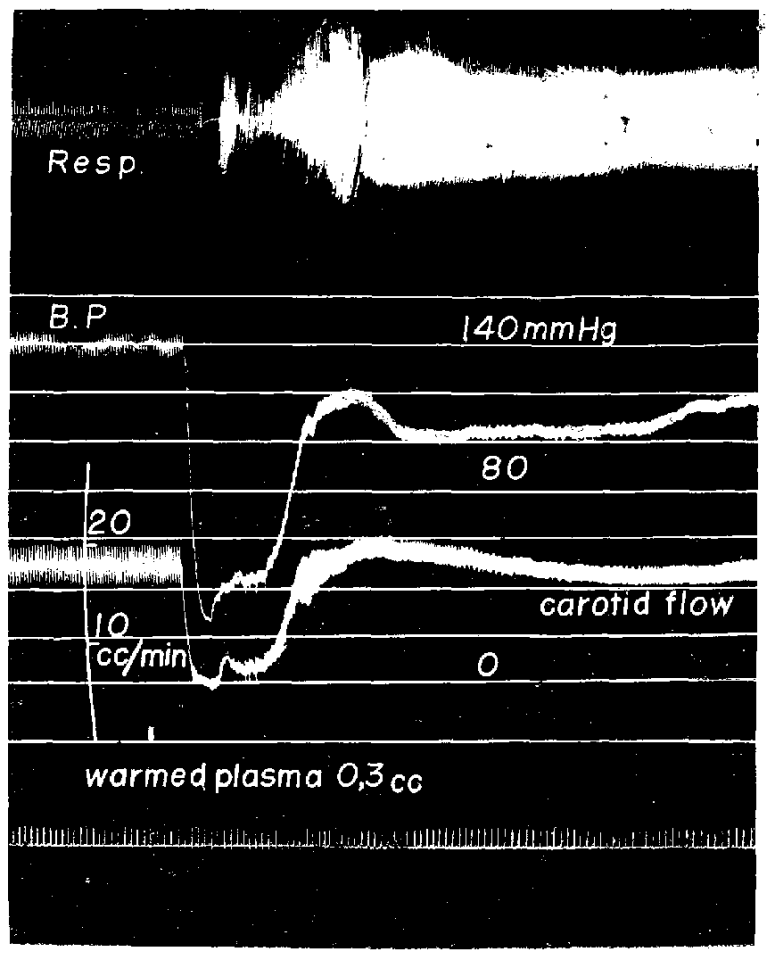

FIG. 3

This lowering of the blood flow is the secondary symptom due to bringing down systemic blood pressure. On the other hand, acetylcholine, histamine, and Kallikrein increased the blood flow of the carotid artery immediately after the intracarotidal injection, which apparently differs from the effect of the warmed plasma. But it was similarly observed that the fall of the blood pressure by these drugs slowed up the blood flow also.

Action on heart movement. Observation of heart movement in situ under artificial respiration was carried out by Cushny's cardiograph. The vertical amplitude of the heart movement was decreased by injection of the warmed plasma, by which the blood pressure had been reduced (Fig. 4). 


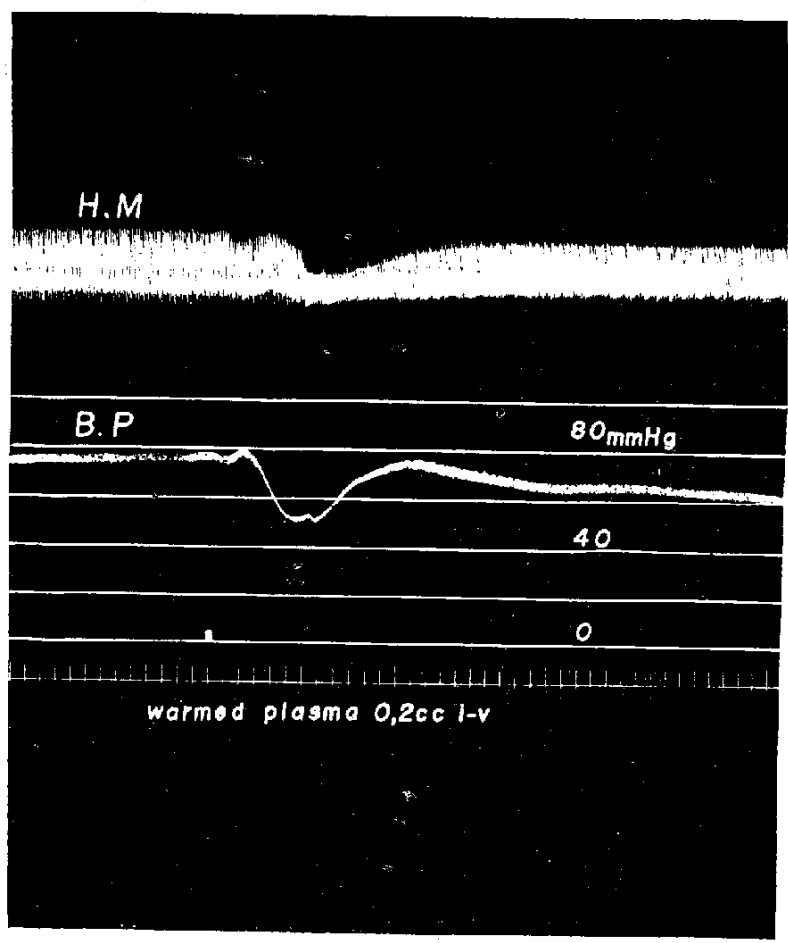

FIG. 4

No effect of the warmed plasma perfused was observed on the isolated cat heart, surviving by Langendorff and Gunn's method.

Action on pulmonary vessels. The measurement of the pulmonary artery pressure was carried out by the rolling manometer in cats thoracotomized under artificial respiration. The warmed plasma raised remarkably the pulmonary artery pressure while it brought down as markedly the systemic blood pressure (Fig. 5).

Isolated cat lungs were perfused in the right ventricle with Ringer's solution at a pressure of $140 \mathrm{~mm} \mathrm{H}_{2} \mathrm{O}$ in a humid room at $37^{\circ} \mathrm{C}$. Fujita's droptimer (27) was used for measurement of the volume of the perfused solution dropping from a glass tube. The inner pressure of bronchi was measured by tambour connected with trachea at the same time. When the warmed plasma was injected into the rubber tubing connected with the pulmonary artery, a number of drops markedly decreased but inner pressure of bronchi increased (Fig. 6).

\section{Physico-chemical significances of zoarmed plasma}

The natural texture of plasma is too complicated to separate completely the active constituents mentioned above. Therefore, this experiment examined how the active component of the warmed plasma is changed by chemical or physico-chemical procedures.

Elimination of protein. The blood pressure test was carried out with the residual constituents excluding protein. To eliminate protein from the plasma, the following reagents or methods were used : ethanol, trichloracetic acid, tannic acid, McHenry's technique for extraction of his- 


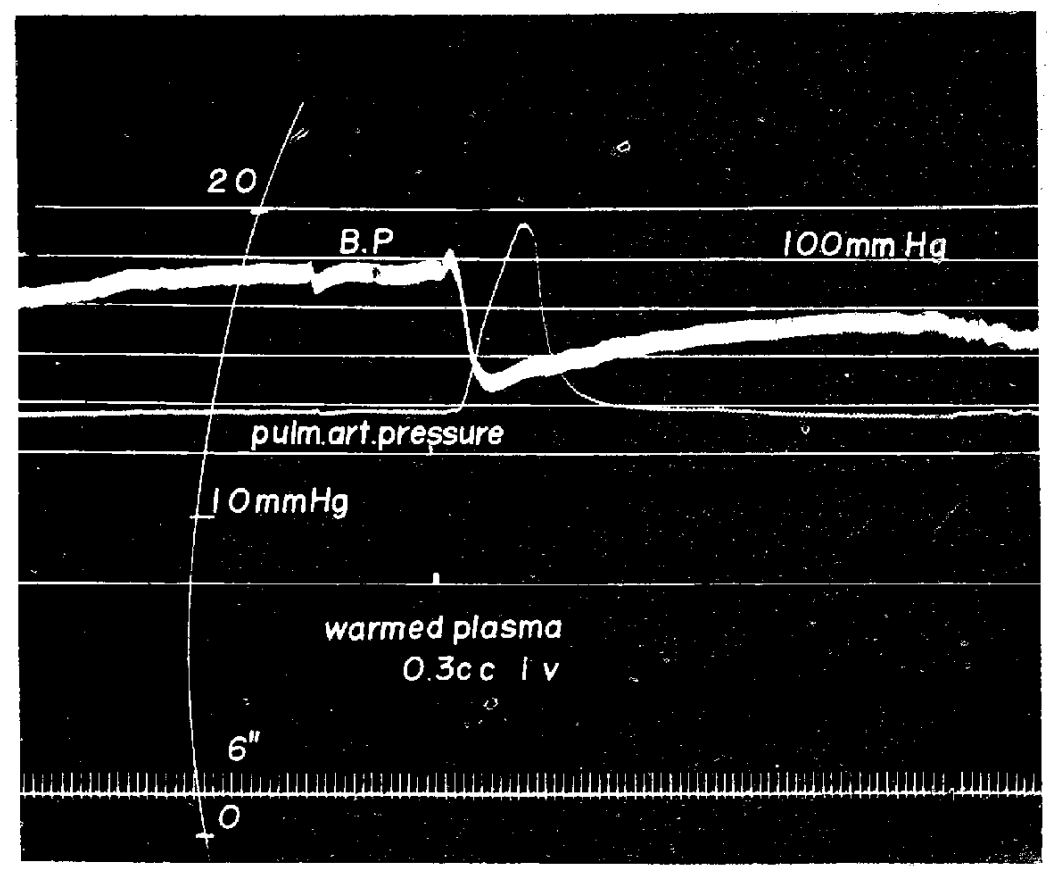

FIG. 5

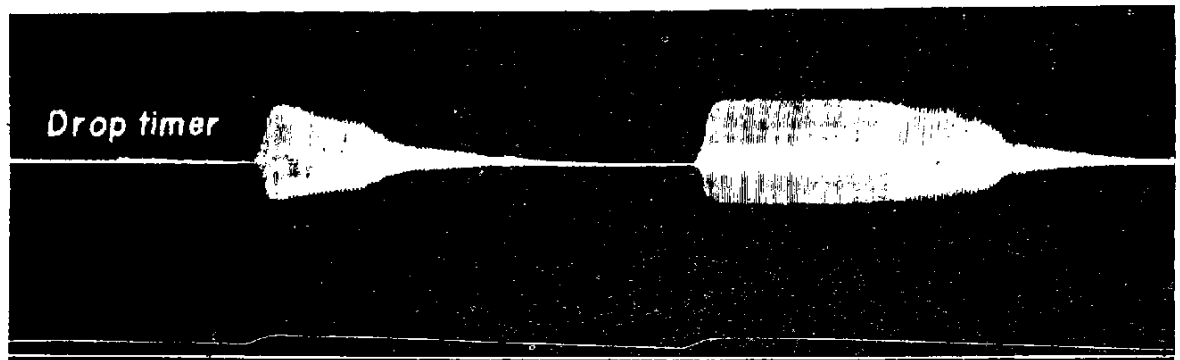

bronch.pressure

tis

drop signal

se

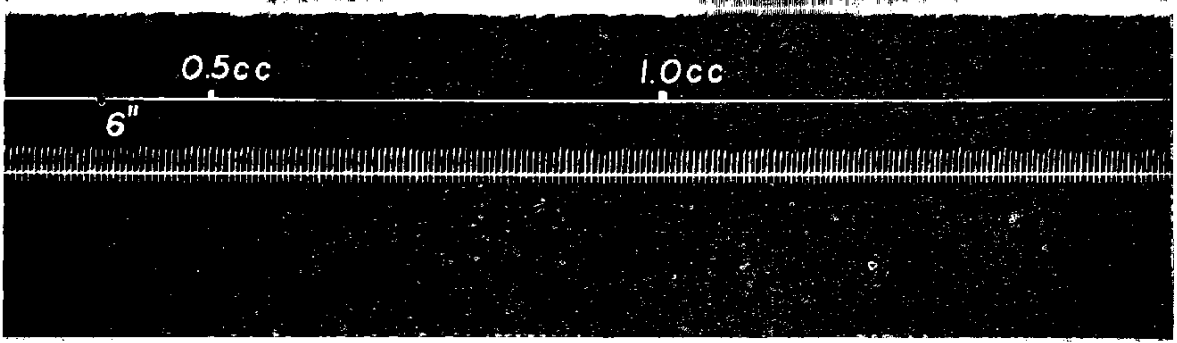

FEG. 6 
tamine (28), Code's method for histamine detection (29), Barsoum-Gaddum's method for detection of adenosin (30), and total hydrolysis with hydrochloric acid (31). All these treatments abolished completely the potency of the warmed plasma.

Fxtraction. with some organic solvents. Any substances extracted by ether, chloroform, butanol, or aceton from the warmed plasma showed no effect on the blood pressure of cats.

Adsorption. Although the warmed plasma was treated by active carbon or kaolin, it did not lose the same potency as did those not so treated. But the potency of the warmed plasma was lost by passage through IRC-50 regulated at $\mathrm{pH} 7$ with ammonium acetate. Elution of the active substance with ammonia solution from IRG-50 was not successful. The same treatment with IRC-50 was carried out for pepton, acting similarly hypotensive on cat blood pressure. The activity of pepton was lost by the IRC-50 treatment, but it recovered by elution with ammonia. From the above results it is clear that the active substance of warmed plasma is not pepton.

Paper partition chromatography. When the warmed plasma was washed in acetic acid, butanol, aqua dest. $(1: 4: 1)$ as a solvent, no difference was observed in its color spots by ninhydrin development between normal fresh plasma and the warmed plasma.

Miscellaneous. The activity of the warmed plasma was reduced to half in formol solution of $1 / 2,000 \mathrm{~mol}$ and completely lost at over $1 / 400 \mathrm{~mol}$. It was lost by heating at $100^{\circ} \mathrm{C}$ for 1 min and by placing it in trypsin solution at $\mathrm{pH} 7.3-7.8$ for 24 hours. Nevertheless, no decrease of the activity occurred by dialysis with collodium membrane in flowing water for 72 hours.

\section{DISCUSSION}

In the above results it is perceived that the rabbit plasma or serum separated before blood coagulation is not effective on blood pressure of the cat, though serum of the rabbit and some other animals is said to be primarily toxic to the cat (13-15). The toxicity seems to be due to histamine in serum. But the plasma becomes markedly hypotensive on blood pressure after keeping it at $35^{\circ}-40^{\circ} \mathrm{C}$ for over 18 hours. This was called "warmed plasma."

It has been known that there are some substances in blood, which lower the blood pressure. Histamine seems most possible. Code (32) and others (33-35) have reported that histamine is released easily in plasma after such processes as blood coagulation, cell injury, hemolysis, shaking, and centrifugation in high speed. Barsoum (36) and others (37-40) have observed that blood of the rabbit contains larger quantities of histamine than that of other animals. Nishiyama (41) and others (42-44) have observed that the blood pressure of cats is most sensitive to histamine contained in $1.0 \mathrm{cc}$ of rabbit blood capable to lower the cat blood pressure by $40-60 \mathrm{~mm} \mathrm{Hg}$.

Two chemical tests. (McHenry's and Code's method) were made with the warmed plasma in order to release histamine, but it could not be detected in the plasma. The hypotensive action of the warmed plasma is not affected by an antihistaminic, benadryl, which has to block the preliminary action of histamine, so that characteristics of the warmed plasma are very much unlike those of histamine. 
According to the result of the experiment in which the warmed plasma is administered into the carotid artery, and that of the experiment with a spinal cat, it is clear that the vasodepressive effect is not on the brain but of a peripheral nature. The blood flow of the carotid and femoral artery is decreased when the systemic blood pressure falls after administration of the warmed plasma. The hypotensive action of the warmed plasma shows no change under occlusion of abdominal circulation, so it has to be considered: that pulmonary circulation has been affected: The pressure of pulmonary artery rises and the pulmonary vessels constrict obviously, which is perceived in decreasing drop numbers in the experiment of the isolated lungs. So the disturbance of heart movement, after administering the warmed plasma, is caused by elevating the vascular resistance in pulmonary circulation because the isolated cat heart is by no means affected by perfusion of the warmed plasma. It is concluded that the lowering of the cat's blood pressure by the warmed plasma is due to constriction of of pulmonary vessels.

Next, acetylcholine and ATP are possible active constituents appearing in the blood. They are also known as agents which increase the resistance of pulmonary vessels, and bringing down

TABLE 1

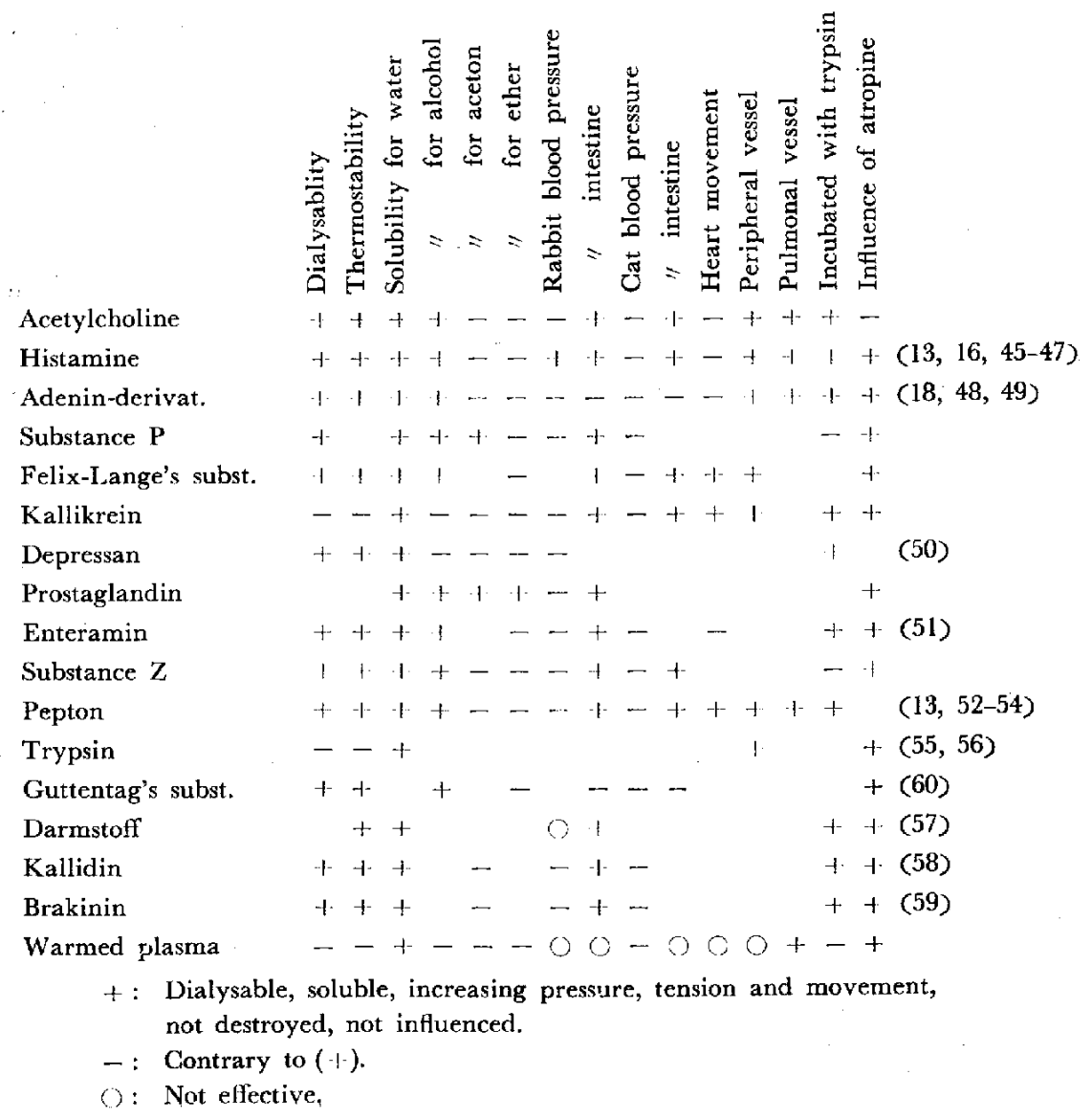


the blood pressure of the cat. But these substances dilate peripheral vessels, except these of the lungs, and they are effective on isolated intestines. The other differences are noted in the table. The warmed plasma is by no means identical with these substances.

The active constituent of the warmed plasma was examined by some physico-chemical experiments. It is undialysable by collodium membrane, inactivated by trypsin, lost by eliminating protein with various technique and by formol solution. It is very unstable and not effective pharmacologically except on blood pressure of the cat. The comparison with similar substances concerning various properties is shown in the table.

It is considered that an active constituent, a new substance, may be produced in enzymatic processes at $35^{\circ}-40^{\circ} \mathrm{C}$ from plasma protein.

\section{SUMMARY}

1. The rabbit plasma separated before blood coagulation does nothing to a cat's blood pressure, but it becomes markedly hypotensive after having been kept at $37^{\circ} \mathrm{C}$ for over 18 hours.

2. The activation of plasma is observed also in the human blood, as well as in cat blood.

3. This hypotensive action on the blood pressure is caused by a disturbance of the heart, due to the constriction of pulmonary vessels.

4. The hypotensive substance of warmed plasma differs ffrom histaminc, acetylcholine, ATP, etc.

\section{REFERENCES}

1) Zipf, K. AND Wagenfeld, F.: Arch. exper. Path. u. Pharmakol. 150, 70 (1930)

2) TRendelenburg, P.: Pflügers Arch. 203, 413 (1924)

3) Freund, H.: Arch. exper. Path. u. Pharmakol. 86, 266 (1920); 88, 39 (1922)

4) HAAKE, E.: Ibid. 150, 119 (1930)

5) O'CONNOR, J.K.: Ibid. 67, 195 (1912)

6) Mosso, A.: Ibid. 25, 111 (1889)

7) BRODIE, J.G.: J. Physiol. 26, 48 (1900-1901)

B) Bernstein, J.: Pfiugers Arch. 15, 575 (1877)

9) DOERR, R.: Kolle-Wassermanns Handb. 1, 888 (1929)

10) LOEBE, L. et al.: Virchows Arch. 201, 5 (1910)

11) EDMUNDS, C.W.: Z. Immun. Forsehg. 22, 181 (1934)

12) Kawamata, S.: Hokkaido Igaku Zassi 12, 93 (1934)

13) ABE, K.: Tohoku I gaku Zassi 4, 19 (1914)

14) DRINKER, G.K.: J. Immunol. 9, 384 (1924)

15) MANWARNING, W.H. et al.: JAMA 80, 1437 (1923)

16) DALE, H.H. AND DUDLEY, H.W.: J. Physiol. 68, 97 (1929)

17) ALLES, G.A.: Physiol. Rev. 14, 276 (1934)

18) Drury, A.V. AND SzEnT-Györgyi, A.: J. Physiol. 68, 213 (1929)

19) Fray, E.K. and Kraut, H.: Arch. exper. Path. u. Pharmakol. 133, 1 (1928)

20) EULER, U.S.: Ibid. 181, 181 (1936)

21) WERLE, E. AND ERDöS, E.G.: Ibid. 223, 234 (1954) 
22) Felix, K. AND LANGE, F.: Ibid. 164, 402; 417 (1932)

23) EULER, U.S.: Ibid. 175, 78 (1937)

24) Rocha E Silva, M. et al.: Amer. J. Physiol. 156, 261 (1949)

25) Hongo, T. AND UENo, A.: Folia pharmacol. japon. 50, 481 (1954)

26) Ueno, A. And Takenaka, F.: Jap. J. Pharmacol. 4, 98 (1955)

27) SHIMAMOTO, K. et al.: Folia pharmacol. japon. 50, 393 (1954)

28) BeST, C.F. AND MCHenRy, E.W.: J. Physiol. 70, 349 (1930)

29) CODE, C.F.: Ibid. 89, 257 (1937)

30) BARSOUM, G.S. AND GADDUM, J.H.: Ibid. 85, 1 (1935)

31) ZIPF, K. AND HÜlsmeYer, P.: Arch. exper. Path. u. Pharmakol. 173, 1 (1933)

32) CODE, C.F.: J. Physiol. 90, 349 (1937)

33) Emmelin, N.G.: Acta Physiol. Scandinav. 2, 1 (1945)

34) Starling, E.H.: Proc. Roy. Soc. London 97, 321 (1925)

35) ANREP, G.V. et al.: J. Physiol. 96, 130 (1939)

36) BARSOUM, G.S. AND SMIRK, T.H.: Clin. Science 2, 337 (1936)

37) CODE, C.F.: J. Physiol. 88, 101 (1936)

38) CODE, C.F. AND Jansen, J.L.: Amer. J. Physiol. 131, 768 (1941)

39) Rocha E Silva, M. : Ibid. 143, 314 (1945)

40) Rose, B.: Proc. Soc. Exper. Biol. \& Med. 42, 494 (1941)

41) NishiYaMA, I.: Folia pharmacol. japon. 35, 17 (1941)

42) Feldberg, W. AND Scilf, F.: Histamin, Julius Springer, Berlin (1930)

43) BEST, C.H.: J. Physiol. 67, 526 (1926)

44) Burn, J.H.: Cited from Feldberg, W. AND Scilf, E. (42)

45) JanuschKe, E. AND POLlaK, L.: Arch. exper. Path. u. Pharmakol. 66, 205 (1911)

46) BACHER, V.G. AND PICK, E.P.: Ibid. 74, 65 (1913)

47) TrToN, F.P.: Pflügers Arch. 155, 77 (1914)

48) Szent-Györgyı, A. : Amer. J. Physiol. 90, 536 (1929)

49) Wedd, A.M. AND FENN, W.O.: J. Pharmacol. \& Exper. Therap. 47, 365 (1936)

50) WollKeim, F. AND LANGE, F.: Disch. med. Wschr. 1, 573 (1932)

51) Erspamer, V.: Arch. exper. Path. u. Pharmakol. 196, 343 (1940)

52) BABASAKI, Y.: Folia pharmacol. japon. 16, 18 (1933)

53) POPIELSKI, L.: Pfiugers Arch. 130, 394 (1909)

54) KaUFMANN, E.: Zentralbl. f. Physiol. 27, 724 (1913)

55) WERLE, E,W. ct al.: Arch. exper. Path. u. Pharmakol. 225, 365 (1955)

56) WERLE, E.W.: Biochem. Z. 301, 429 (1939)

57) VOGT, H. AND KUCH, W.: Arch. exper. Path. u. Pharmakol. 209, 71 (1950)

58) WERLE, E.W. et al.: Biochem. Z. 289, 217 (1939)

59) Rocha E Silva, M. et al.: Amer. J. Physiol. 156, 261 (1949)

60) GUTTENTAG, O.E.: Arch, exper. Path. u. Pharmakol. 162, 727 (1931) 